\title{
LA CARA NEOEXTRACTIVISTA DE LA CRISIS SOCIO-AMBIENTAL EN SUDAMÉRICA: ACENTUACIÓN DEL DESPOJO, DISPUTA DE TERRITORIALIDADES Y HORIZONTES ALTERNATIVOS
}

\section{THE NEOEXTRACTIVIST FACE OF THE SOCIO-ENVIRONMENTAL CRISIS in SOUth AMERICA: aCCENTUATION OF DISPOSSESSION, DISPUTE OF TERRITORIALITIES AND ALTERNATIVE HORIZONS}

Fecha recepción: 21 de septiembre de 2020 / fecha aceptación: 29 de diciembre de 2020

Pabel C. López F.1

Cómo citar este artículo:

López, P. (2020). La cara neoextractivista de la crisis socio-ambiental en sudamérica: acentuación del despojo, disputa de territorialidades y horizontes alternativos. Revista Pensamiento y Acción Interdisciplinaria, 6(2), 121-139. http://doi.org/10.29035/pai.6.2.121

\section{Resumen}

En los últimos años se viene discutiendo en diversos ámbitos, en particular desde el pensamiento social crítico, acerca de la inminencia, los orígenes y los alcances de la actual multicrisis global y sus impactos para todo el planeta, con un énfasis central en la dimensión ecológica, sobre todo partir de las señales irrefutables del cambio climático y sus consecuencias. En América del Sur, una manifestación de esta crisis múltiple está estrechamente relacionada al neoextractivismo, que en el último lustro se despliega con una dinámica expansiva. Esta actual fase neoextractivista, a su vez, una acentuación de despojos múltiples pero también de procesos de disputa y re-existencia socioterritorial. En este texto se aborda la dimensión socio-ecológica de la crisis en perspectiva regional sudamericana, a partir de una caracterización de una de su actual fase de exacerbación neo-extractivista, de reactivación de los conflictos socioambientales, movimientos socioterritoriales y la configuración de horizontes alternativos.

Palabras clave: crisis socio-ecológica, neo-extractivismo, conflictos territoriales, alternativas

1 Investigador asociado al Postgrado en Ciencias del Desarrollo (CIDES-UMSA) en Bolivia. Doctor en Sociología por la Scuola Normale Superiore (SNS) y la Universidad de Milán 'Bicocca' en Italia. Postdoctorante en el Instituto de Estudios de América Latina y el Caribe de la Universidad de Buenos Aires (IEALC-UBA). Integrante y ex coordinador del Grupo de Trabajo "Territorialidades en disputa y re-existencia" del Consejo Latinoamericano de Ciencias Sociales (CLACSO). Correo electrónico: velpalopezflo@gmail.com 
La cara neoextractivista de la crisis socio-ambiental en Sudamérica: acentuación del despojo, disputa de territorialidades y horizontes alternativos por Pabel López F.

\begin{abstract}
In recent years there has been a discussion in various fields, particularly from critical social thinking, about the imminence, origins and scope of the current global multi-crisis and its impacts on the planet, with a central emphasis on the ecological dimension, especially from the irrefutable signs of climate change and its consequences. In South America, a manifestation of this multiple crisis is closely related to neo-extractivism, which in the last five years has been unfolding with an expansive dynamic. This current neoextractivist phase, in turn, an accentuation of the multiple dispossessions but also of processes of socio-territorial dispute and re-existence. This text addresses the socio-ecological dimension of the crisis from a South American regional perspective, based on a characterization of one of its current phase of neo-extractivist exacerbation, reactivation of socio-environmental conflicts and socio-territorial movements, as well as the configuration of alternative horizons.
\end{abstract}

Keywords: socio-ecological crisis, neo-extractivism, territorial conflicts, alternatives

\title{
Introducción
}

En la actualidad es posible señalar que no existe región del mundo que no se vea enfrentada a una crisis múltiple, o multicrisis, de escala planetaria (Acosta \& Brand, 2017), así como a un aumento en la conflictividad socio-ambiental. Sea esto atribuible a las condiciones globales como el cambio climático, la distribución asimétricas de roles productivos a escala global, o a situaciones a nivel nacional y regional, como son las transformaciones territoriales, falta de regulación ambientales o nuevas regulaciones. América Latina, como parte del Sur Global, se enfrenta en la actualidad a diferentes crisis, donde la cuestión social y la ecológica surgen problemáticas centrales, ésta última determinante no solo para la región, sino también para el futuro de todo el planeta. En este escenario, la dificultad radica en que casi todas las respuestas frente a cuestiones sociales y ambientales continúan predominantemente orientadas al crecimiento económico promovido por concepciones y modelos de desarrollo de base moderna, antropocéntrica, colonial, capitalista y patriarcal, que conduce a una aceleración del colapso ecológico del planeta (Burchardt, 2018; Lander \& Arconada, 2019; Svampa \& Viale, 2020). Con ello, proliferan conflictos socio-ecológicos que demuestran la discrepancia de sociedades entre la dependencia del modelo de desarrollo (neo-) extractivista y aspiraciones de descolonializar y democratizar la relación sociedad-naturaleza.

Hace dos décadas en América del Sur comenzó un cambio de época (Svampa, 2013), a la vez que también se han venido manifestando continuidades, ambigüedades, avances y retrocesos en los diversos contextos de los países de la región; en unos casos, a la persistencia de formatos político-económicos neoliberales; en otros, a procesos político-estatales con señales 'post-neoliberales' y con gobiernos denominados "progresistas". Sin embargo, en la mayoría de los países de la región se trata de contextos caracterizados por la acentuación de modelos económicos de base extractivista y de reprimarización económica, 
asentados en la explotación/exportación de recursos naturales necesarios para el modelo global de consumo que se expande en el Norte como en el Sur global. Se basa en explotar la naturaleza y la mano de obra a escala mundial, externalizando costos sociales y ecológicos, e intensificando las modalidades de acumulación capitalista vigente. Este escenario parece acentuarse desde hace, al menos un lustro, con un periodo marcado por la caída de los precios de algunos commodities en el mercado global, repercutiendo en la región con la expansión de las fronteras neo-extractivistas (Svampa, 2019a) hacia nuevos territorios antes considerados "improductivos". Dicha expansión estaría generando transformaciones sociales y territoriales de gran magnitud, en la medida en que reorienta completamente la economía de grandes espacios territoriales y de pueblos enteros, así como de sus territorialidades y de sus formas de vida, dentro de las nuevas reconfiguraciones espaciales y sus dinámicas de acumulación del capitalismo global. Una muestra de ello, es la situación de comunidades campesinas, pueblos indígenas, comunidades costeras y afro-descendientes que luchan específicamente por la defensa de sus derechos culturales, económicos y territoriales ante el avance de territorialidades extractivistas basadas en la exclusión y el despojo, o lo que se ha denominado como 'acumulación por desposesión' (Harvey, 2004), como un proceso que ha colocado en disputa el territorio, el medio-ambiente y la condición de vida de pueblos enteros.

En ese sentido, hace algunos años se viene debatiendo sobre el 'neoextractivismo' en América del Sur (Gudynas, 2012), que estaría consolidando la condición dependiente de la región, en tanto abastecedora de materias primas, en el marco de un nuevo 'consenso de los commodities' (Svampa, 2013), que vino produciendo, a la vez, la activación de conflictos sociales, territoriales, ambientales y culturales. Este fenómeno ha configurado, en gran parte de la región, un contexto de fuerte tensión, contestación y disputa entre movimientos socio-ecológicos con los Estados y gobiernos, donde éstos últimos reaccionan; ya sea retrocediendo en emprendimientos extractivos o apropiándose en parte de estas demandas sociales; o intensificando sus políticas y expandiendo proyectos extractivos, lo que produce a su vez aumento de la tensión y de los conflictos socio-ambientales (Martinez-Alier \& Walter, 2016) y genera, al mismo tiempo, escenarios de violencia, represión y criminalización de la protesta social.

Dentro de ese contexto, la actual proliferación del Covid-19 como pandemia y crisis sanitaria global, reveló y profundizó las deficiencias estructurales preexistentes en casi todos los países de la región, así como las tremendas injusticias socioeconómicas y las asimetrías globales. Variados síntomas de una crisis múltiple y generalizada, incluidos los históricos, crónicos e irresueltos clivajes económicos, políticos, territoriales, geopolíticos, culturales, con los problemas sociales y ecológicos como centrales, ya afectaban de manera desproporcionada a sectores marginados de la sociedad. Tal situación, previa a la explosión de la pandemia del nuevo coronavirus, fue provocando y acumulando un malestar social y territorial generalizado en varios países de América Latina. 
Malestar presente en la región desde 2019, a través de estallidos o rebeliones sociales y procesos destituyentes en varios países. Asimismo, desde el inicio del milenio, se ha registrado un número creciente de conflictos socioecológicos en conexión directa con actividades extractivistas, sin excepción de las diferentes orientaciones políticas, ya sean de perfil neoliberal o progresista. Esto ha llevado, a su vez, al aumento de espacios y procesos de resistencia y re-existencia en toda América Latina, que se convirtió en un lugar relevante para movimientos socioambientales y disputa de territorialidades, como también de luchas societales con implicancias ontológicas y epistemológicas, de otras racionalidades ambientales (Leff, 2018) y de modos de vida alternativos a la lógica civilizatoria del capital. Se trata de un pluriverso de procesos que van desde formas de r-existencia (PortoGonçalves \& Leff 2016) hasta alternativas generalizadas como post-extractivistas, las cuales resultan urgentes dentro de los horizontes posibles para enfrentar la crisis múltiple, sobre todo en su faceta actual de colapso socio-ecológico.

En este breve texto se propone un abordaje a la actual multi-crisis global desde su dimensión socio-ecológica y en perspectiva regional sudamericana, a partir de la caracterización de una de sus manifestaciones: la actual fase de exacerbación neo-extractivista y de reactivación de los conflictos socioambientales y movimientos socioterritoriales, así como la configuración de horizontes alternativos y propuestas post-extractivistas y su potencialidad como salidas a la actual crisis civilizatoria.

\section{La dimensión socio-ecológica de la multicrisis civilizatoria}

Como vienen advirtiendo varias voces de alerta, tanto en el Sur y el Norte Global, estamos presenciando una profunda crisis civilizatoria (Acosta \& Brand, 2017; Brand \& Wissen, 2018; Chakrabarty, 2018; Lander, 2019; Svampa \& Viale, 2020). En ese sentido, principalmente desde América Latina, se ha planteado la pregunta: ¿Cuál es la dimensión civilizatoria de esta crisis? Siguiendo a Lander (2019) El momento actual puede entenderse como una crisis terminal del patrón civilizador de la modernidad colonial, que puede ser caracterizado como antropocéntrico, patriarcal, clasista, racista y cuyos patrones hegemónicos de conocimiento, lejos de ofrecer respuestas de salida a esta crisis civilizatoria, contribuyen a profundizarla. Se trataría, también, de una configuración histórica de la modernidad, basada en un crecimiento sin fin y "una guerra sistemática contra los factores que hacen posible la vida en el planeta Tierra" (Lander 2019, p. 26). Según esta lectura, las diferentes dimensiones del patrón de civilización hegemónica no son independientes, sino que, por el contrario, se refuerzan entre sí. La civilización de la dominación/apropiación sobre la "naturaleza", a, cuya máxima expresión histórica es el capitalismo, que habría llegado a sus límites.

Por su parte, Moore (2015) propone pensar la situación actual de crisis múltiple como una crisis de la ecología-mundo, lo que sugiere que la modernidad 
no actúa sobre la naturaleza sino que se desarrolla a través del propio tejido de la vida, lo que permite nombrarlo como 'capitalismo en el tejido de la vida' (Moore 2015). En esta perspectiva, al situar las transformaciones socioecológicas actuales dentro de los patrones modernos de recurrencia y evolución, a largo plazo y a gran escala, es posible ver e iluminar las contradicciones en juego en la actual multicrisis. Por lo tanto, pensar en el capitalismo como una ecología mundial nos permitiría comprender las naturalezas históricamente específicas de la modernidad como tejidos de liberación y limitación. Lo que sugiere la siguiente pregunta: “¿Estamos en un punto de inflexión en el capitalismo histórico, no solo en una crisis del desarrollo, sino una crisis de época?" (Moore, 2015, p. 46).

Para comprender el carácter multidimensional de la crisis actual y abrir un campo de reflexión sobre alternativas igualmente multidimensionales, Brand y Wissen (2018) han introducido el concepto de Modo de Vida Imperial, para dar sentido a los patrones dominantes de producción, distribución y consumo, pero también de los imaginarios culturales, subjetividades y rutinas arraigadas en las prácticas cotidianas, es decir en la modalidades del actual metabolismo social, en el marco del orden civilizatorio capitalista. De esta manera, dicho concepto busca conjugar dimensiones estructurales con dimensiones subjetivantes y subjetivas (Brand \& Wissen 2018). Además, los autores se refieren al modo de vida capitalista occidental moderno que prevalece entre las mayorías del Norte global, pero también, y cada vez más, entre las clases altas y medias del Sur global y los países "emergentes". Es imperial en la medida en que ya que presupone acceso ilimitado a recursos naturales, mano de obra barata, capacidades para absorber contaminación y basura, así como espacio ilimitado en el planeta para solo una minoría de la población mundial (Lang \& Hoetmer, 2019), "externalizando los costos ecológicos y sociales" (Brand \& Wissen, 2018, p. 12). En esta línea de análisis, la multi-crisis civilizatoria actual se debe a la continua expansión de un Modo de Vivir Imperial, en un planeta con demostrados límites físicos, para ello, los modos de vida solidarios adquieren especial relevancia: es decir, "formas de organizar las sociedades alejadas del camino trazado por el paradigma de desarrollo y por la triada desarrollo-crecimiento-progreso" (Lang \& Hotmer, 2019, p. 82).

Asimismo, Svampa (2019b) relaciona los debates sobrela multicrisis civilizatoria con las lecturas actuales sobre el Antropoceno/Capitaloceno como un debate central en alusión a la crisis asociada al inminente colapso ecológico (Svampa \& Viale, 2020). En ese marco, el Antropoceno, como concepto umbral (bisagra), más que una nueva era geológica, designa un nuevo periodo, en el cual el ser humano representa una fuerza transformadora con alcance e impacto planetario, y cuya influencia ha implicado, precisamente el ingreso a esta nueva era. A la vez, instala la idea de que hemos traspuesto un umbral peligroso y, acaso, irreversible, cuyas manifestaciones serían alarmantes. Al mismo tiempo, el Antropoceno constituye una categoría síntesis, esto es un punto de convergencia interdisciplinaria, donde "los grandes cambios de origen antrópico o antropogénico que hacen peligrar la vida en el planeta están directamente ligados a la dinámica de acumulación del 
capital y a los modelos de desarrollo dominantes y cuyos efectos, precisamente se revelan en la actual crisis socio-ecológica" (Svampa \& Viale, 2020, p. 24).

En ese entendido, en los últimos años, se hace cada vez más evidente que atravesamos una crisis socio-ecológica y una emergencia climática a nivel global sin precedentes. Junto, a un mayor convencimiento de llegar a los límites naturales y ecológicos del planeta y, consecuentemente, de que la actual relación capital-naturaleza es insostenible. Algunos factores de alarma de la actual crisis socio-ecológica global, que justifican hablar del pasaje a una nueva era/ umbral, según Svampa \& Viale, (2020), serian: 1) El Cambio climático, asociado al calentamiento global, evidentes con fenómenos climáticos extremos y sin precedentes; 2) La pérdida de biodiversidad y la destrucción del tejido de vida y de los eco-sistemas acelerada por el cambio climático (extinción masiva de especies, acidificación de los océanos, desertificación acelerada de la tierra, deforestación, etc.); 3) Cambios en los ciclos biogeoquímicos, fundamentales para mantener el equilibrio de los ecosistemas (ciclo del carbono, del nitrógeno, del oxígeno, del agua, etc.), esenciales para la reproducción de la vida, como la fotosíntesis o la polinización, que ya están afectados; 4) Cambios en los modelos de producción y consumo (esquemas de obsolescencia precoz y programada, modelos alimentarios a gran escala, basada en agro-negocio: expansión de la frontera agrícola y ganadera, aumento de monocultivos, deforestación, acaparamiento de tierras, contaminación del agua y la tierra, uso de transgénicos, etc.). Estos son algunos de los factores que reflejan el aumento exponencial de impactos ecológicos de origen antrópico, sobre todo a partir de la mitad del siglo XX, y con gran acentuación las últimas dos décadas, mediante la exacerbación de un tipo de metabolismo social que impulsa la extracción desenfrenada de recursos no renovables, destruye la biodiversidad, impacta y cambia los ciclos de la naturaleza, fomenta un patrón de consumo irresponsable e insostenible y modelos alimentarios insustentables.

Tal como señala Svampa (2019b), existe una profusa bibliografía acerca del colapso civilizatorio, un campo que desafortunadamente en la actualidad revela una gran potencialidad explicativa. En ese sentido, muchos especialistas postulan que el ecocidio, nombrado recientemente en nuestra región por el movimiento del pueblo Mapuche en Argentina como "terricidio", es la mayor amenaza que pesa sobre la sociedad mundial. En América del Sur, los impactos de la crisis socioecológica están directamente relacionados con la crítica al neoextractivismo (Gudynas, 2012; Svampa, 2013 y 2019a); y la visión hegemónica del desarrollo puesto que, "es en la periferia globalizada donde se expresa a cabalidad la mercantilización de todos los factores de producción, a través de la imposición a gran escala de modelos de desarrollo insustentables" (Svampa, 2019a, p. 159). 


\section{Manifestación de la crisis socio-ecológica en la región: Neoextractivismo exacerbado, recolonización territorial y despojos múltiples.}

Una premisa pertinente y general para pensar y problematizar la dimensión socio-ecológica de la actual multicrisis civilizatoria, que se asume en este texto, consiste en la necesidad de dar cuenta de los anclajes territoriales y de los contextos geográficos y temporales concretos en donde se manifiesta y despliega la crisis socio-ecológica global. Esto implica la elección de una clave de lectura y problematización situada y localizada de la crisis en nuestra región. Con ese propósito, se aborda la perspectiva del neoextractivismo como categoría que permite caracterizar los procesos y dinámicas de acumulación capitalista y de apropiación, explotación/destrucción de la naturaleza en América Latina en general, pero particularmente acentuada en América del Sur. En ese sentido, se aborda el neoextractivismo en tanto actualización de este modo de acumulación en el siglo XXI en la región, que se relaciona a nuevas dimensiones globales, regionales, territoriales y políticas.

En este contexto se viene debatiendo el neoextractivismo², el cual se caracteriza básicamente por: a) la producción de commodities con el fin de ser exportados al mercado internacional; b) la generación de importantes impactos socio-ambientales; c) el impulso de proyectos de gran escala; d) el involucramiento de grandes empresas trasnacionales; y e) la generación de economías externas y grandes rentabilidades para las corporaciones (Gudynas, 2012 y 2015; Svampa, 2019). Desde una perspectiva crítica, el término Neoextractivismo critica y problematiza patrones de desarrollo insostenible y la lógica de un despojo en expansión, combinando problemas multiescalares y diferentes dimensiones de la crisis actual (Svampa 2019a, p. 14). Así, el neoextractivismo, como parte constitutiva del capitalismo y su compulsión de acumulación, necesita a la vez de un exterior extraeconómico ya que "integra constantemente nuevos territorios, campos, relaciones sociales y mercados de futuro" (Composto \& Navarro 2014, p. 35) y se materializa en la expansión de las fronteras de productos básicos en territorios previamente considerados improductivos. Este proceso se considera como acumulación por despojo (Harvey 2004), que es un aspecto central del proceso continuo de colonización, descolonización y recolonización (Makaran \& López, 2018).

El neoextractivismo, también puede ser considerado en un marco y dinámica glocal; porque está fuertemente condicionado por la globalización, y a factores internacionales como "la demanda, los precios o las inversiones, que son determinantes y fundamentales para sus procesos de expansión y contracción, aunque siempre están anclados localmente" (Gudynas 2018, p.

2 Por 'Neoextractivismo' se entiende al modelo de desarrollo económico adoptado por algunos gobiernos de América del Sur desde principios del siglo XXI. Al igual que en el extractivismo convencional, el neoextractivismo orienta la economía hacia las actividades de explotación intensiva de la naturaleza para la obtención de recursos no procesados, o escasamente procesados, dirigidos de forma prioritaria a la exportación a gran escala, pero con un papel más protagónico del Estado en el proceso productivo, permitiendo la obtención de un porcentaje mayor de ingresos para las arcas estatales. Parte de esos recursos son destinados a programas sociales que dotan a los gobiernos de cierto grado de legitimidad (Gudynas, 2012). 
21). Desde una perspectiva crítica, el término neoextractivismo se convierte en una categoría útil para explicar y analizar las relaciones y disputas de poder subyacentes, así como las responsabilidades compartidas entre el Norte y el Sur globales. Desde la época colonial, América Latina se ha integrado al mercado mundial como exportador de recursos naturales, reproducido hoy en día con "sus relaciones asimétricas, intercambio desigual y con una división del trabajo internacional y territorial consolidada" (Svampa 2019a, p. 15). Fundado en un patrón de poder basado en jerarquías raciales, epistemológicas y culturales. En ese sentido, la expansión en curso genera transformaciones sociales y territoriales de gran magnitud, reorientando la economía de grandes espacios territoriales, territorialidades y formas de vida. Esta nueva reconfiguración espacial del capitalismo global se manifiesta principalmente en la continuidad, expansión o intensificación del extractivismo basado en procesos de exclusión y múltiples despojos (Navarro, 2018).

Porencima de las diferencias que es posibleestablecer en términos ideológicos, a partir de las aparentes tendencias diversas de regímenes políticos en el escenario latinoamericano (neoliberales conservadores o neoliberales progresistas), se fue consolidando un modelo de apropiación de la naturaleza, ocupación de territorios, explotación de los bienes comunes y un modo de territorialización, que avanza sobre las poblaciones a partir de una lógica vertical descendente. Esto significa un retroceso para los avances en el campo de la democracia participativa, e inaugura un nuevo ciclo de criminalización y violación de los derechos humanos (Mantovani \& Svampa, 2019). En ese escenario, es posible dar cuenta de un proceso de acentuación/exacerbación del neo-extractivismo en casi toda la región, que se manifiestan principalmente a partir de dinámicas de expansión e intensificación de las fronteras de la minería, en particular a cielo abierto; de la explotación hidrocarburíferas, en especial mediante la modalidad del fracking; de la frontera agroindustrial y el uso de transgénicos; la proliferación de megahidroeléctricas, entre las principales. Paralelamente, con las nuevas modalidades de expansión de las fronteras del capital, en general los conflictos socio-ecológicos también se fueron multiplicando y las resistencias sociales se hicieron más activas y organizadas. Mantovani \& Svampa (2019) proponen distinguir tres fases del neoextractivismo en la región, como una imagen dinámica y cambiante de los procesos de interacción entre gobiernos y conflictividad socioambiental, bajo el ciclo progresista (y más allá). Estás son:

1) La fase de positividad. Esta sería una fase caracterizada más bien por un proceso de configuración del neoextractivismo como tal, luego de un ciclo intenso de impugnación del neoliberalismo en la región (Thwaites Rey \& Ouviña, 2019) de la mano con el despliegue del ciclo progresista). Se trata de un periodo que desarrolla entre 2003 y 2008, relacionado a lo que Svampa (2010) denomino como el comienzo del 'cambio de época' y con el boom del precio de los commodities. En ese contexto desde varios gobiernos en el subcontinente se leyó al giro neoextractivista en términos de ventajas comparativas, como un 
'nuevo desarrollismo', más allá de las diferencias entre gobiernos progresistas o neoliberales/conservadores. Asimismo, se trató de una fase de positividad porque el aumento del gasto social y su impacto en la reducción de la pobreza, el creciente rol del Estado y la ampliación de la participación de lo popular generaron grandes expectativas en la sociedad, sobre todo luego de décadas de estancamiento económico y ajuste neoliberal.

2) La fase de la multiplicación de los megaproyectos. Esta segunda fase, que comprendería aproximadamente entre 2008 y 2013-2015 y se trataría de un periodo de consolidación neo-extractivista, blanqueo del "consenso de los commodities" (Mantovani \& Svampa, 2019) y de derrumbe del mito progresista como alternativa. En consonancia con las resistencias sociales, el núcleo de este periodo aparece reflejado en los planes nacionales de desarrollo presentados por los diferentes gobiernos, que enfatizaron en el incremento de diferentes actividades extractivas, según la especialización del país, fueran estas la extracción de minerales, de petróleo, las centrales hidroeléctricas o la expansión de los cultivos transgénicos. Este incremento de megaproyectos se expresó, siguiendo a Mantovani \& Svampa (2019), también a través la Iniciativa para la Integración de la Infraestructura Regional Suramericana (IIRSA), Ilamada luego COSIPLAN. Esta segunda etapa nos inserta en una abierta conflictividad en los territorios extractivos, de proliferación de conflictos socioambientales que superaron el encapsulamiento local y adquirieron una visibilidad nacional, como aquel en torno al proyecto de una carretera que atravesara el TIPNIS en Bolivia; la construcción de la mega-represa de Belo Monte (Brasil); la pueblada de Famatina y las resistencias contra la mega-minería en Argentina, o la suspensión final de la propuesta Yasuní en Ecuador. En este periodo, la expansión de la frontera de derechos (colectivos, territoriales, ambientales) alcanzada en la fase de positividad, encontró un límite en la expansión creciente de las fronteras de explotación del capital, lo que daría cuenta de las profundas contradicciones de las narrativas emancipatorias, desmintiendo la retoricas de los "progresismos".

3) Fase de exacerbación del neo-extractivismo. En un periodo que iría aproximadamente desde 2013/2015 hasta la actualidad, se caracteriza fundamentalmente por la acentuación de los procesos de despojos múltiples (Navarro, 2018) y el aumento de la violencia en los territorios, lo que marcaría un desplazamiento hacia la configuración de un híperextractivismo (Gudynas, 2015). En continuidad con la segunda fase, asistimos a una exacerbación del neoextractivismo, donde uno de los elementos relevantes que explica esta línea, en términos de su continuidad agravada, se refiere a la caída de los precios de las materias primas, que impulsó a los gobiernos latinoamericanos a incrementar aún más los proyectos extractivos y ampliar las fronteras de los commodities (Moore, 2015; Mantovani \& Svampa, 2019). Asimismo, esta fase coincide con el declive y el denominado 'fin del ciclo progresista' (Svampa, 2019a; Lander, 2018), así como un sensible retrocesos de derechos colectivos y un aumento de la violencia contra las resistencias sociales y ambientales, entre otros aspectos. Este 
escenario hará más evidente la convergencia entre la expansión extractivista; mayores flexibilizaciones y desregulaciones paulatinas en las pautas y acuerdos de explotación, y la intensificación de la externalización socioambiental sobre la población y los territorios (Mantovani \& Svampa, 2019).

En el contexto regional que se fue configurando a partir de las sucesivas fases mencionadas, a pesar de los muchos matices según cada caso, es posible afirmar que parte del actual mapa sociopolítico y geopolítico sudamericano es resultado, en parte, de los escenarios de un neoextractivismo que se viene reconstituyendo a partir del agotamiento/fin del ciclo progresista, en donde se hace evidente un proceso incontrastable de destrucción acelerada de biodiversidad. Expresada, por ejemplo, en los incendios forestales provocados, sin precedentes en su extensión y afectación biocida, por la expansión de las fronteras agrícola, ganadera del agronegocio (particularmente en Bolivia, Brasil, Argentina y Paraguay). A su vez, se viene produciendo una reconfiguración de la relación entre las transformaciones en los mecanismos de acumulación de capital y de apropiación de la naturaleza (principalmente en los países con gobiernos los progresismos), los patrones de gobernabilidad y control social, o nuevos conflictos socioambientales y disputas territoriales, donde las fronteras del derecho se retraen en sintonía con un sensible aumento de la violencia hacia territorios y hacia movimientos y líderes sociales. Es decir, se asiste al avance de la violencia extractivista de la mano con la instalación de estados de excepción y expansión de fuerzas conservadoras y reaccionarias (giro a la derecha extrema).

El contexto político latinoamericano de este nuevo periodo del neoextractivismo es accidentado, inestable, volátil y de intensas disputas nacionales, regionales y geopolíticas. Si en varios países latinoamericanos emergieron regímenes "progresistas", como alternativa al neoliberalismo, hoy esa alternativa se ha transformado en una suerte de "neoliberalismo transgénico" (Mantovani \& Svampa, 2019), en tanto se aplican políticas propias del neoliberalismo, instrumentadas y moldeadas por el propio "progresismo" latinoamericano, utilizando la fortaleza del Estado. También en la ampliación y profundización de los extractivismos, que ha llegado a niveles incluso no alcanzados por los anteriores gobiernos neoliberales.

\section{Conflictos socioecológicos, cosmovisiones en tensión y territorialidades en disputa}

Una de las consecuencias de la actual inflexión extractivista es la explosión de conflictos socioambientales, que se evidencia particularmente en la potenciación de las luchas ancestrales por la tierra, protagonizadas por movimientos indígenas, campesinos y comunidades rurales, así como en el surgimiento de nuevas formas de movilización y participación ciudadana, centradas en la defensa de lo común, la biodiversidad y el ambiente con un marcado protagonismo de las mujeres. En ese marco, dadas sus características, la conflictividad socio-ambiental puede ser 
pensada como inherente al neoextractivismo y no como su consecuencia, aun si esto no se traduce en todos los casos por la emergencia de resistencias sociales.

A pesar del incremento de dinámicas extractivas expansivas y de acentuación de despojos múltiples en gran parte del subcontinente, este fenómeno ha tenido como su reverso la resistencia y el germen de la movilización, generando un fenómeno de reconstrucción de una identidad 'etno-territorial', un 'giro ecoterritorial' de las luchas y los movimientos sociales en la región (Svampa 2013) y la activación de 'nuevas territorialidades' (Porto-Gonçalves, 2010), en algunos casos asociadas a la defensa de los derechos territoriales colectivos, como base donde los pueblos indígenas estructuran sus reivindicaciones, organización y demandas, así como su identidad colectiva, y desde donde se organiza la acción colectiva. Precisamente frente a esta nueva asonada capitalista y recolonizadora en los territorios y territorialidades de casi todas las geografías del 'Abya Yala' (América Latina), se vienen produciendo también multiplicidad de resistencias socioterritoriales y luchas comunitarias, en gran medida protagonizada por pueblos, comunidades y organizaciones indígenas, lo que produce y visibiliza, a su vez, una proliferación de conflictos socioecológicos, de movimientos comunitarios, luchas por el territorio y por lo común y de territorialidades en disputa, y en este sentido se viene gestando una nueva 'ecología política' (Humphreys \& Bebbington, 2012), así como de nuevos lenguajes de valoración (Svampa, 2016) e imaginarios de r-existencia (Escobar, 2018). Como señala Maristella Svampa,

“[...] Al calor del nuevo siglo XXI, el fenómeno del extractivismo adquirió nuevas dimensiones, no solo objetivas - por la cantidad y la escala de los proyectos, los diferentes tipos de actividad, los actores nacionales y transnacionales involucrados-, sino también de otras subjetivas, a partir de la emergencia de grandes resistencias sociales, que cuestionaron el avance vertiginoso de la frontera de los commodities y fueron elaborando otros lenguajes y narrativas frente al despojo, en defensa de otros valores -la tierra, el territorio, los bienes comunes, la naturaleza[...]Al mismo tiempo, la dimensión de disputa y de conflicto introducida por la nueva dinámica de acumulación del capital basada en la presión sobre los bienes naturales, las tierras y los territorios [...]" (Svampa 2019a, p. 12).

De particular modo, las nuevas dinámicas y recientes políticas estatales y gubernamentales de carácter extractivista en la región andino-amazónica ha provocado crecientes y, en ocasiones violentos, enfrentamientos entre los pueblos indígenas con los gobiernos. Así, "el espacio-tiempo del capital pretende imponerse sobre los espacios-tiempos de los pueblos y comunidades [...]. La nueva empresa colonizadora se presenta hoy más ambiciosa que la de antaño, puesto que esta vez pretende expandirse más allá de sus lugares tradicionales e imponerse de manera irreversible y definitiva" (Makaran \& López 2018, p. 18). De 
esa manera, la colonialidad territorial de estos órdenes espaciales hegemónicos, hoy defendidos por los dogmas del "desarrollo" y la "superación de la pobreza" o la simple necesidad del crecimiento económico y "productivo", en realidad lo que habría generado y ahora se hace más visible con la actual pandemia son condiciones de mayor exclusión, dominación, pobreza y desigualdad, racismo cultural, exclusión, devastación social y ambiental, entre otros males.

Como fuese, América Latina está siendo sometida por el capitalismo transnacional neoliberal a un reordenamiento territorial y a procesos de desterritorialización / reterritorialización que intenta arrollar resistencias y autonomías, consolidando su condición colonial y dependiente de abastecedora de materias primas al mercado global, en lo que Svampa (2013) denominó como el 'consenso de los commodities'. Dicho orden, a pesar del reciente derrumbe internacional del precio del petróleo y otros commodities, configura parte de la geopolítica global en la actualidad y fue consolidando un estilo de "desarrollo neo-extractivista" en América del Sur (Svampa, 2019a), tensionando aún más el arco entre la competitividad por ventajas comparativas y la activación de conflictos sociales, territoriales, ambientales y culturales, particularmente en aquellos espacios locales donde se reproducen territorialidades y formas de vida comunitaria. Situación que, con la actual pandemia, lejos de cambiar o detenerse se ha acentuado y/o consolidado en toda América Latina. Este fenómeno, a su vez, ha configurado en gran parte de la región un contexto de fuerte tensión, contestación y disputa entre movimientos socio-ecológicos con los Estados y gobiernos, donde éstos últimos reaccionan; ya sea modificando (retóricamente) emprendimientos extractivos o apropiándose (discursivamente) en parte de estas demandas o ya sea intensificando sus políticas y expandiendo proyectos extractivos, lo que produce a su vez un aumento de la tensión y de los conflictos socio-ambientales (Martínez-Alier \& Walter, 2016) y genera al mismo tiempo escenarios de violencia, represión y criminalización de la protesta social.

Sin embargo, a pesar de su arraigo en manifestaciones localmente situadas y en anclajes geográficos específicos, es necesario señalar que los conflictos socioecológicos son "glocales", en la medida en que los procesos, actores y dispositivos de poder nacionales y globales, así como las disputas sobre los sistemas económicos y los entendimientos del desarrollo, se materializan como dinámicas de extracción global y como formas de activismo, resistencia y movilización en conflictos situados. La forma en que las disputas moldean realmente la vida local está influenciada por la relación de fuerzas locales, que están arraigadas en las historias locales y la atribución de significado a los procesos a escala global (Lang \& Hoetmer, 2019). En esa línea, Dietz \& Engels (2020) enfatizan la necesidad de una contextualización radical a la hora de analizar los conflictos extractivos, pues cada conflicto tiene su propia lógica, historia y reglas. Refiriéndose al "campo de conflicto", estas autoras brindan un marco para hacer accesibles los conflictos al análisis empírico y contextualizarlos considerando dinámicas globales, nacionales y locales. Los cambios y problemas globales afectan el campo del conflicto de 
manera indirecta, mediada por cambios estructurales (Dietz \& Engels 2020), que solo dentro de un determinado contexto se vuelven relevantes para la acción.

Entonces, al abordar los conflictos socio-ambientales en la región, se precisa pensar en procesos conectados, actores diversos, visiones contrapuestas y dispositivos de poder globales, regionales y nacionales que se manifiestan en la expansión de dinámicas de extracción y el incremento o profundización de conflictos locales. A su vez, implica pensar las disputas de construcción de sentido, diversos concepciones del mundo y el territorio, sobre las relaciones/ integraciones ser humano/naturaleza, (incluyendo consecuencias ecológicas, identidades y prácticas tradicionales, modos de vida, visiones de desarrollo). Por ende, es necesaria una especificidad analítica con una perspectiva espaciotemporal de los conflictos y, a la vez, un análisis multiescalar (Escobar, 2014), que plantea que tanto el modo de acumulación como los conflictos pueden ser estudiado desde el ámbito social y territorial.

\section{Horizontes Alternativos: post-extractivismo, post-desarrollo y post-capitalismo}

Como suele suceder durante los períodos de crisis, se alimentan crecientemente la discusión respecto de alternativas al sistema dominante. En América del Sur, al menos en los países "progresistas", esta discusión parecía superada luego de la crisis neoliberal; pero hoy, nuevamente, va tomando fuerza, ante el agotamiento del ciclo "progresista" y la renovada arremetida conservadora, que fue alimentada por los propios gobiernos "progresistas". En el marco del neoextractivismo, la dinámica de las resistencias socioambientales o socio-ecológicas y los movimientos socioterritoriales asentó las bases de un lenguaje común de valoración (Svampa, 2016) sobre la territorialidad, algo que se denominó como "giro eco-territorial" (Svampa, 2013). Este expresa la convergencia de diferentes matrices y lenguajes, a partir del cruce innovador entre matriz indígena-comunitaria y narrativa autonómica, en clave ambientalista. 'Buen Vivir', 'bienes comunes', 'comunalidad', 'derechos de la naturaleza', 'autonomía' y 'ética del cuidado' son algunos conceptos/horizontes que diseñan este nuevo lenguaje.

Si bien el comienzo del ciclo progresista estuvo marcado por el protagonismo de las luchas populares y comunitarias, y la elaboración de un lenguaje emancipatorio tuvieron como gran actor a los pueblos indígenas (Buen Vivir, derechos de la naturaleza, autonomía, Estado plurinacional), hacia el final del ciclo progresista aparece signado por las luchas de las mujeres, en diferentes escalas y niveles, visibles también en las resistencias contra el neoextractivismo. Esta tendencia acompaña y suma a la narrativa del Buen Vivir y de los derechos de la naturaleza, el lenguaje ecofeminista del cuerpo/territorio, la ética del cuidado y la afirmación de la interdependencia. Así, a la narrativa de la descolonización, asociada al momento indígena, se añade el nuevo ethos feminista, que une mujer y territorio, con la crítica al patriarcado y la ética del cuidado. Estas potentes 
narrativas, matrices y formas de lucha se enfrentan a nuevos desafíos, transitan nuevos rumbos y se desarrollan bajo nuevas condiciones materiales. Los impactos en los tejidos sociales señalan no solo los nuevos escenarios del neoextractivismo, sino también de la producción y posibilidades de lo común, como ámbito privilegiado para la acción colectiva, cooperativa y para la reproducción de la vida frente a la crisis socioecológica.

Es posible apuntar que diversos procesos sociales transformadores y emblemáticos se vienen manifestando y desarrollando en todo el mundo, con particular densidad en el Sur Global, ya que han sido capaces de cambiar sus realidades sociales situadas de múltiples maneras. De forma simultánea, como señalan Lang \& Hoetmer (2019), estos procesos han logrado abordar diferentes ejes de dominación y anticipar formas de organización social que configuran alternativas a las lógicas mercantilizadoras, patriarcales, coloniales y destructivas del capitalismo moderno. Tal como apuntan Acosta \& Brand (2017) al ser la actual crisis múltiple, una crisis demasiado compleja, las posibles soluciones también lo son. De ese modo, las experiencias sociales/societales alternativas de las que se podrían dar cuenta a lo largo y ancho de la región también se presentan y manifiestan en un marco de pluralidad, heteronomía y diversidad geográfica y contextualmente situada, lo que plantea a la vez un desafío cognitivo al momento de abordar y analizar la variedad de procesos de construcción alternativa.

En ese sentido, tal como apuntan Svampa \& Viale (2020), las alternativas al modelo de desarrollo dominante hoy en América Latina y su vínculo con la globalización asimétrica no son nuevas en la región ni únicas en el mundo, pero sin duda la envergadura y vertiginosidad de los proyectos que masivamente se implementan en el continente, han puesto en alerta máxima a organizaciones, activistas e intelectuales del más diverso cuño sobre la necesidad de elaborar propuestas alternativas viables, que sin dejar de tomar en cuenta los modelos y experiencias ya existentes, se planteen en una escala más general, a nivel nacional, regional y global (Svampa \& Viale, 2020). En varios países de América Latina existen debates sobre las alternativas al extractivismo que proponen la hipótesis de la transición, desde una matriz de escenarios de intervención multidimensional.

En América Latina se viene produciendo históricamente, desde espacios sociales, comunitarios y populares, algo que es parte singular e innovador para pensamiento crítico, que implica una ruptura contra-hegemónica, tanto epistémica como practica y concreta, a través del despliegue de procesos sociales, particularmente de carácter socioterritorial y en algunos casos de alcance societal. Por una parte, mediante experiencias de construcción de una heteronomía autonómica de densidad comunitaria y popular, lo que implica una nueva gramática autonómica que se entiende como una deconstrucción teóricopráctica alternativa y alterativa de los modos de existencia hegemónicos impuestos por el neocolonialismo, el capitalismo y el Estado nación. Por otra parte, varios de esos procesos se manifiestan como movimientos societales (Tapia, 2008) y/o 
se expresan simplemente como procesos de re-existencia socioterritorial, es decir, a través de experiencias en las que actores sociales no solo activan formas específicas, y espacialmente situadas de resiliencia ante los nuevos escenarios de despojo múltiple y reconfiguración territorial en sus entornos y condiciones de vida, sino también a través de formas y estrategias que les permite la construcción o re-construcción de relaciones socioterritoriales de su vida colectiva.

En lo que se refiere a las experiencias de re-existencia que se manifiestan en diversas geografías de América Latina, las mismas se relacionan a relaciones y procesos socio-territoriales que no surgen solo como reacción a una dinámica expansiva de territorialidades extractivas y a la acentuación de procesos de despojo múltiple en toda la región, sino que en su gran mayoría se trata de procesos que históricamente se presentan como modos de organización de la vida colectiva, en algunos casos, como formas pre-existentes al propio capitalismo como orden civilizatorio y que persisten, resisten y se recrean continuamente. Dentro de esta perspectiva, estos procesos de resistencia se convierten en movimientos para la r-existencia. Estos grupos no solamente resisten el despojo y la des-territorialización, ellos redefinen sus formas de existencia a través de movimientos emancipatorios y la reinvención de sus identidades, sus modos de pensar, y sus modos de producción y de sustento (Porto-Gonçalves \& Leff, 2015). Así, estos procesos de re-existencia se manifiestan y despliegan una diversidad y pluralidad de casos en América Latina, las mismas que se presentan, entre tantas varias formas, en las experiencias de agroecología comunitaria campesina, indígena o campesino-indígena, en las formas de gestión comunitaria de gestión territorial, en la silvicultura y manejo integral de territorios comunitarios reconocidos, en las formas de protección y gestión agroforestal de bienes comunes.

\section{Conclusiones}

La actual crisis sanitaria global por la pandemia del Covid-19 ha puesto de relieve las tremendas desigualdades estructurales y las injusticias históricas producidas por múltiples factores. Estas relaciones, por un lado, están revelando y acentuando las asimetrías históricas y sistemáticas preexistentes entre el "Norte" y el "Sur Global". Por otro lado, están intensificando las marcadas diferencias sociales que caracterizan el desarrollo de la fase neoliberal del capitalismo y hacen innegable sus profundos efectos, agudizando las tensiones y desequilibrios acumulados en el ciclo previo al estallido de la pandemia Covid-19. Ya antes de la pandemia de Covid-19, América Latina estaba experimentando algunos síntomas agudos y múltiples de una crisis generalizada, también multifacética, particularmente de carácter sociopolítico y socioambiental. Esta crisis puede entenderse como expresión regional de una multicrisis civilizatoria global (Lander, 2018), que ha desencadenado un malestar social generalizado, manifestado en una ola de protestas y movilización de amplios sectores de la sociedad, particularmente visibles en las rebeliones sociales en Chile, Ecuador, Colombia, Brasil, Bolivia, Perú desde 2019 hasta la actualidad. 
En ese marco, atravesamos una crisis socio-ecológica y una emergencia climática a nivel global, sin precedentes en la historia, que permiten afirmar que el tan enunciado 'colapso ecológico' ya llego (Svampa \& Viale, 2020). Tal como señalamos en este trabajo, la actual crisis socio-ecológica forma parte de una crisis del patrón civilizatorio hegemónico (Lander, 2018), con base en la episteme de la modernidad y el paradigma del "desarrollo" y de un "progreso" sin fin, y que en breve puede ser caracterizado como antropocéntrico, capitalista, desarrollista, patriarcal, colonial, clasista, racista y 'terricida', como algunos de sus principales rasgos a escala global. Precisamente, en el marco de la crisis ecológica y con la instalación generalizada del calentamiento global como uno de sus efectos más visibles y mediáticamente más difundidos, se ha expandido el concepto del Antropoceno para caracterizar nuestra época, que va más allá de una simple era geológica y se coloca como un concepto umbral, que daría cuenta no solo del origen antropogénico de la actual emergencia ambiental y colapso ecológico (Svampa \& Viale, 2020). También de los peligrosos límites que se habrían traspasado en relación a la capacidad naturales del planeta y de los procesos de regeneración y reproducción de los ecosistemas de vida (Leff, 2018). Más allá de las diferencias en los enfoques y los debates al respecto, lo que resultaría indiscutible es asistir a una crisis y emergencia socio-ecológica sin precedentes, de orígenes antrópicos y con efectos para todas las formas de vida en el planeta, la que indudablemente ha sido acelerada por los parámetros históricos de las dinámicas de acumulación capitalista, que presenta diversas manifestaciones, según la geografía y el contexto de que se trate.

Para el contexto que aquí nos interesa, esta dimensión socio-ecológica de la crisis en las dos últimas décadas, presenta características y dinámicas en América del Sur, donde las modalidades de apropiación y explotación de la naturaleza y los procesos acentuación de formas de despojos múltiples, directamente relacionados a los cambios y reconfiguraciones de las dinámicas de acumulación capitalista, se fueron expandiendo y/o intensificando, principalmente por la consolidación y generalización de modelos de desarrollo y políticas estatales con base en enclaves y emprendimientos neo-extractivistas. Particularmente en América Latina, durante estos últimos años se han acentuado los procesos de apropiación, mercantilización, sometimiento y destrucción de la naturaleza, así como las dinámicas de alteración/ afectación de los ciclos naturales de reproducción de la vida para someterlos a las exigencias de los procesos de acumulación del capital en la región. Por lo tanto, sugerimos un marco para el análisis integral, contextual y temporal, a partir de enfoques y discusiones actuales desde o sobre América Latina, vinculados a la relación interdependiente entre procesos neo-extractivistas, tanto de regímenes de corte neoliberal-conservadores como de perfil neoliberal-progresistas, con los conflictos socio-ecológicos, en el marco de los procesos actuales de acumulación del capital en los territorios, que en este trabajo se identifica como la cara neoextractivista de la actual crisis socio-ecológica en la región. 


\section{Referencias bibliográficas}

Acosta, A., \& Brand, U. (2017). Salidas del laberinto capitalista. Decrecimiento y postextractivismo. Madrid: Icaria

Brand, U., \& Wissen, M. (2018). The Limits to Capitalist Nature: Theorizing and Overcoming the Imperial Mode of Living. Transforming Capitalism Series Editors. New York: Rowman \& Littlefield International.

Burchardt, H. J. (2018). Bienestar del tiempo: respuesta latinoamericana frente a la crisis socioecológica. Nueva Sociedad, (273), 136-150.

Chakrabarty, D. (2015). The Anthropocene and the Convergence of Histories. En C. Hamilton, C. Bonneuil, \& F. Gemenne (Eds.). The Anthropocene and the Global Environmental Crisis: Rethinking Modernity in a New Epoch. (44-56). Londres/New York: Routledge

Composto, C., \& Navarro, M. (2014). Claves de lectura para comprender el despojo y las luchas por los Bienes Comunes Naturales en América Latina. En VVAA (2014). Territorios En Disputa. Despojo Capitalista, Luchas En Defensa de Los Bienes Comunes Naturales y Alternativas Emancipatorias Para América Latina. (33-75). México, D. F.: Bajo Tierra

Dietz, K., \& Engels, B. (2020). Analysing Land Conflicts in Times of Global Crises. Geoforum 111, 208-17. DOI: https://doi.org/10.1016/j. geoforum.2020.02.019.

Escobar, A. (2018). Designs for the Pluriverse: Radical Interdependence, Autonomy, 137 and the Making of Worlds. Duke University Press.

Gudynas, E. (2012). Estado compensadory nuevos extractivismos. Las ambivalencias del progresismo sudamericano. Nueva Sociedad, (237), 128-146.

Gudynas, E. (2015). Extractivismos. Ecología, economía y política de un modo de entender el desarrollo y la naturaleza. Cochabamba: CLAES / CEDIB

Harvey, D. (2004). El "nuevo" imperialismo: acumulación por desposesión. Socialist Register. Buenos Aires: CLACSO.

Humphreys, D., \& Bebbington, A. (2012). Post-what? Extractive industries, narratives of development and socio-environmental disputes across the Andean region. En H. Haarstad, (Ed.). New Political Spaces in Latin American Natural Resource Governance. (17-37). New York: Palgrave Macmillan.

Lander, E., \& Arconada, S. (2019). Crisis Civilizatoria. Experiencias de Los Gobiernos Progresistas y Debates En La Izquierda Latinoamericana. Guadalajara: CALAS. 
Lang. M., \& Hoetmer, R. (2019). Buscando alternativas más allá del desarrollo, Introducción. En M. Lang, C. König, \& A. Regelmann (Eds.) Alternativas en un mundo de crisis: Grupo de Trabajo Global Más Allá del Desarrollo. (8-27). Quito: Fundación Rosa Luxemburg /UASM.

Leff. E. (2018). El fuego de la vida. Heidegger ante la cuestión ambiental. México: Siglo XXI.

Mantovani, T., \& Svampa, M. (2019). En las fronteras del cambio de época Escenarios de una nueva fase del extractivismo en América Latina. En K. Gabbert, \& M. Lang (Eds). ¿Cómo se sostiene la vida en América Latina? Feminismos y re-existencias en tiempos de oscuridad (169-218). Quito: Fundación Rosa Luxemburg/Ediciones Abya-Yala.

Makaran, G., \& López P. (2018). Recolonización en Bolivia. Neonacionalismo y resistencia comunitaria. México: Bajo Tierra, El Colectivo, Plural.

Martínez-Alier J., \& Walter M. (2016). Social Metabolism and Conflicts over Extractivism. En F. de Castro, B. Hogenboom, \& M. Baud (Eds.) Environmental Governance in Latin America. (58-85). London: Palgrave Macmillan.

Moore, J. (2015). Capitalism in the Web of the Life: Ecology and the Accumulation of Capital. Londres/Nueva York: Verso.

Navarrro, M. (2018). Despojo múltiple y separaciones del capital sobre el tejido de la vida. En F. Sierra (Ed). Teoría del valor, comunicación y territorio. (227- 296). Madrid: Siglo XXI.

Porto-Gonçalves, C. W. (2010). Territorialidades y lucha por el territorio en América Latina: Geografía de los movimientos sociales en América Latina. Caracas: IVIC

Porto-Gonçalves, C.W. \& Leff, E. (2015). Political Ecology in Latin America: the social reappropriation of nature, the reinvention of territories and the construction of an environmental rationality. Desenvolvimento e Meio Ambiente,(35), 6588.

Svampa, M. (2013). Consenso de los "Commodities" y lenguajes de valoración en América Latina. Nueva Sociedad, (244), 30-46

Svampa, M. (2016). Debates Latinoamericanos. Indianismo, Desarrollo, Dependencia y Populismo. Buenos Aires: Edhasa.

Svampa, M. (2019a). Las Fronteras Del Neoextractivismo en América Latina. Conflictos Socioambientales, Giro Ecoterritorial y Nuevas Dependencias. Guadalajara: CALAS / Universidad de Guadalajara. 
Svampa, M. (2019b). El Antropoceno como diagnóstico y paradigma. Lecturas globales desde el Sur. Utopía y Praxis Latinoamericana, 24(84), 33-54.

Svampa, M. \& Viale, E. (2020). El colapso ecológico ya llego. Una brújula para salir del (mal)desarrollo. Buenos Aires: Siglo XXI.

Tapia, L. (2008). Política Salvaje. Buenos Aires: CLACSO, Waldhuter.

Thwaites Rey, M., \& Ouviña, H. (2019). El ciclo de impugnación al neoliberalismo en América Latina. En H. Ouviña, \& M. Thwaites Rey (Comp.). Estados en disputa, (17-63). Buenos Aires: El Colectivo, Bajo Tierra, Desde Abajo, Zur.

Dirección de correspondencia:

Pabel C. López F.

Contacto: velpalopezflo@gmail.com 